\title{
Bee Hive Algorithm to Optimize Multi Constrained Piecewise Non-Linear Economic Power Dispatch Problem in Thermal Units
}

\author{
B. Padmanabhan ${ }^{1}$, J. Jasper M. E. ${ }^{2}$, and Siva Kumar R. S. ${ }^{3}$ \\ ${ }^{1}$ M.E Power System Engineering, Sardar Raja College of Engineering Tirunelveli Dist \\ ${ }^{2}$ Associate. Professor, Ponjesly College of Engineering Nagercoil \\ ${ }^{3}$ M.E Power System Engineering, Anna University, Coimbatore \\ 12padmanabhan_balu@yahoo.co.in,22mailtojasper@gmail.com, ${ }^{3}$ sivakrs@gmail.com
}

\begin{abstract}
This paper presents application of a Bee Hive Algorithm to Economic Load Dispatch which considers practical constraints and non linear characteristics. The proposed ED formulation includes ramp rate limits, valve loading effects, multiple fuels, equality and inequality constraints, which usually are found simultaneously in realistic power systems. Conventional methods such as Lambda iteration and Base point participation are not able to obtain optimal solution for units having discontinuous fuel cost functions. Bee Hive Algorithm can overcome the difficulties and provides an almost global optimal solution, since they don’t get stuck up at local optimum.
\end{abstract}

Keywords: Economic load Dispatch, Bee Hive Algorithm, Valve-point loading, Ramp rate limits, Multiple Fuels

\section{Introduction}

ECONOMIC Load Dispatch (ELD) seeks “the best” generation for the generating plants to supply the required demand plus transmission losses with the minimum production cost. Improvement in scheduling the units output can lead to significant cost savings. In traditional ELD problems, the cost function of each generator is approximately represented by a simple quadratic function and is solved using mathematical programming based on several optimization techniques such as dynamic programming, Linear programming, homogenous linear programming and quadratic programming methods[2],[3],[4]. However none of these methods may be able to provide an optimal solution and they usually get stuck at a local optimum. Normally the input-output characteristic of modern generating units are highly nonlinear in nature due to valve-point effect [1],[14], [15], [16], [18], [19] ramp-rate limits, Fuel switching [11], [20] etc, having multiple local minimum points in the cost function.

To overcome such difficulties many heuristic search algorithms, such as Genetic algorithm [1], [5], Differential Evolution [6], Tabu search [7], [19], etc., have been proposed to solve ELD problem. These techniques can be used to search the global optimum with any type of objective function and constraints [22]. In this paper, two ED problem for 3 and 10 thermal units with a non smooth fuel cost function [8] are employed to demonstrate the performance of the proposed method with BHA and the results were compared with GA.

The rest of this paper is organized as follows: Section II describes the formulation of an ED problem; while section III explains the standards in BHA. Section IV then details the procedure of handling the BHA. Section V gives the flow chart. Section VI gives the Data and gives the results of the optimization. Section VII outlines our conclusion and future research.

\section{Problem Description}

The objective of ED is to determine the generation levels for all on-line units which minimize the total fuel cost, while satisfying a set of constraints. It can be formulated as follows:

Received: November $2^{\text {nd }}, 2010$. Accepted: March $14^{\text {th }}, 2011$ 


\section{A. Economic Dispatch (Ed) Problem Formulation}

The fuel cost functions of the generating units are usually described by a quadratic function of power output [13].

Thus the objective function is to minimize:

$$
F_{i}\left(P_{i}\right)=a_{i} P_{i}^{2}+b_{i} P_{i}+c_{i}
$$

Where

$a_{i}, b_{i}, c_{i}$ - the fuel cost coefficients of the ith unit

$\mathrm{N}$ - Number of generating units in the system

$P_{i}$ - output generation of ith unit.

\section{Power balance constraint:}

$$
\sum_{i=1}^{N} P_{i}=P_{D}+P_{L}
$$

Where

$P_{D}-$ Total power demand

$P_{L}-$ Total network losses

\section{Capacity limits constraints:}

$$
P_{i}^{\min } \leq P_{i} \leq P_{i}^{\max }
$$

Where

$$
\begin{aligned}
& P_{i}{ }^{\mathrm{min}}-\text { minimum generation limit } \\
& P_{i}{ }^{\mathrm{max}}-\text { maximum generation limit }
\end{aligned}
$$

B. Valve Point Effect

Large steam turbine generators will have a number of steam admission valves that are opened in sequence to obtain ever-increasing output of the unit. As the unit loading increases the input to the unit increases and the incremental heat rate decreases between the opening points for any two valves [9], however, when a valve is first opened, the throttling losses increases rapidly and the incremental heat rate rises suddenly. This is "valve point" effect which leads to non-smooth, non-convex input-output characteristics [12], to be solved using the heuristic techniques[1].

The valve point effect is incorporated in ED problem by superimposing the sine component model on the quadratic cost curve which is given below,

$$
F_{i}^{*}\left(P_{i}\right)=F_{i}\left(P_{i}\right)+e_{i} \sin \left(f_{i}\left[P_{i}^{\min }-P_{i}\right]\right)
$$

Where

$F_{i}{ }^{*}\left(P_{i}\right)-$ fuel cost if ith unit with

valve point effect

$e_{i}, f_{i}$ - the fuel cost coefficients of the ith unit with valve point effect. 


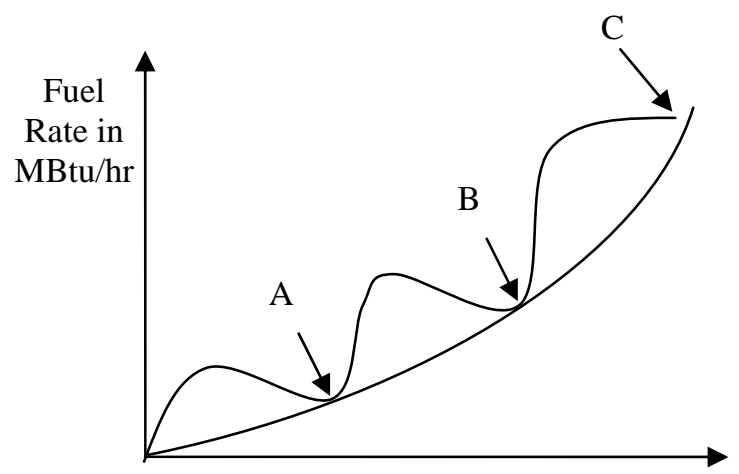

Generations in MW

Figure 2.1. Valve point curve

\section{Ramp Rate Limits:}

The Ramp-Up and Ramp-Down rate limits of $i^{\text {th }}$ generator are given by As generation increases,

$$
P_{i}-P_{i 0}<=U R_{i}
$$

As generation decreases

$$
P_{i}-P_{i 0}<=D R_{i}
$$

and

$$
\max \left(P_{i}^{\min }, P_{i 0}-D R_{i}\right)<=P_{i}<=\min \left(P_{i}^{\max }, P_{i 0}+U R_{i}\right)
$$

Where $\mathrm{Pi}$ is the current output power and $\mathrm{Pi} 0$ is the output power in the previous interval of the $i^{\text {th }}$ generator unit. $\mathrm{UR}_{\mathrm{i}}$ is the up-ramp rate limit of the $\mathrm{i}^{\text {th }}$ generator and $\mathrm{DR}_{\mathrm{i}}$ is the downramp rate limit of the $i^{\text {th }}$ generator.

\section{Multiple Fuels:}

Some generating units are capable of operating using different types of fuels. The use of multiple fuel types may result in multiple cost curves that are not necessarily parallel or continuous. The lower region of the resulting cost curve determines which fuel type is most economical to bum.

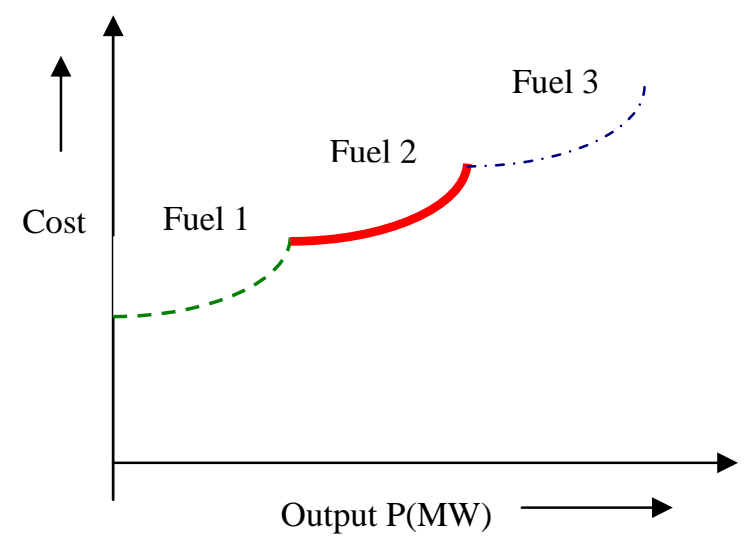

Figure 2.2. Fuel Cost Function Supplied with Multiple Fuel Types 
This cost function can be represented by a piecewise curve (see Fig 2.2), and the segments are defined by the range in which each fuel is used. The ED problem with piece wise quadratic cost curves is very difficult to solve by standard techniques. Piecewise quadratic cost functions have as many segments as fuel types.

$$
F_{i}\left(P_{G, i}\right)=\left\{\begin{array}{cc}
a_{i, 1}+b_{i, 1} P_{G_{i}}+c_{i, 1} P_{G_{i}}{ }^{2}, & \underline{P}_{G_{i}}^{1}<\bar{P}_{G_{i}}^{1} \\
a_{i, 2}+b_{i, 2} P_{G_{i}}+c_{i, 2} P_{G_{i}}{ }^{2}, & \underline{P}_{G_{i}}^{2}<\bar{P}_{G_{i}}^{2} \\
\vdots & \\
a_{i, k}+b_{i, k} P_{G_{i}}+c_{i, k} P_{G_{i}}{ }^{2}, & \underline{P}_{G_{i}}^{3}<\bar{P}_{G_{i}}^{k}
\end{array}\right.
$$

Where $P_{G_{i}}^{k}$ and $\overline{P_{G_{i}}^{k}}$ are the lower and upper bound respectively of the $k^{\text {th }}$ fuel of unit-I, and $a_{i, k}, b_{i, k} ., c_{i, k}$ are the $k^{\text {th }}$ fuel cost coefficient of unit-i.

\section{Optimization Using Bee Hive Algorithm}

Bee Hive algorithm, proposed by Karaboga in 2005 for real parameter optimization, is a recently introduced optimization algorithm and simulates the foraging behavior of bee colony [2] for unconstrained optimization problems [1]-[5]. For solving constrained optimization problems, a constraint handling method was incorporated with the algorithm [7]. The ABC algorithm is developed by inspecting the behaviors of the real bees on finding food source, which is called the nectar, and sharing the information of food sources to the bees in the nest.

\section{Biological Inspiration}

In a real bee colony, there are some tasks performed by specialized individuals. These specialized bees try to maximize the nectar amount stored in the hive by performing efficient division of labour and self-organization. The minimal model of swarm-intelligent forage selection in a honey bee colony, that bee hive algorithm adopts, consists of three kinds of bees: employed bees, onlooker bees, and scout bees. Half of the colony comprises employed bees and the other half includes the onlooker bees. Employed bees are responsible from exploiting the nectar sources explored before and giving information to the other waiting bees (onlooker bees) in the hive about the quality of the food source site which they are exploiting. Onlooker bees wait in the hive and decide a food source to exploit depending on the information shared by the employed bees. Scouts randomly search the environment in order to find a new food source depending on an internal motivation or possible external clues or randomly. The bee decides for one of the possibilities using the mechanism based on the characteristics of the food source (quality, quantity and distance from the hive). The described process continues constantly, while the bees from a hive collect nectar and investigate new areas with possible food sources.

\section{Implementation Of Bee Hive Algorithm}

Main steps of the Bee Hive algorithm simulating these behaviors are given below, here the food represents the economic generation and the food source represents the limits of each generator.

1. Initialize the food source positions.

2. Each employed bee produces a new food source in her food source site and exploits the better source.

3. Each onlooker bee selects a source depending on the quality of her solution, produces a new food source in selected food source site and exploits the better source.

4. Determine the source to be abandoned and allocate its employed bee as scout for searching new food sources. 
5. Memorize the best food source found so far.

6. Repeat steps 2-5 until the stopping criterion is met.

The process of the Bee hive algorithm is presented as follows:

Step 1. Initialization: Spray ne percentage of the populations into the solution space randomly, and then calculate their fitness values, which are called the nectar amounts, where ne represents the ratio of employed bees to the total population. Once these populations are positioned into the solution space, they are called the employed bees.

Step 2. Move the Onlookers: Calculate the probability of selecting a food source, select a food source to move to by roulette wheel selection for every onlooker bees and then determine the nectar amounts of them.

Step 3. Move the Scouts: If the fitness values of the employed bees do not be improved by a continuous predetermined number of iterations, which is called "Limit", those food sources are abandoned, and these employed bees become the scouts.

Step 4. Update the Best Food Source Found So Far: Memorize the best fitness value and the position, which are found by the bees.

Step 5. Termination Checking: Check if the amount of the iterations satisfies the termination condition. If the termination condition is satisfied, terminate the program and output the results; otherwise go back to the Step 2.

$$
P_{i}=\frac{F\left(\theta_{i}\right)}{\sum_{k=1}^{S} F\left(\theta_{k}\right)}
$$

where $\theta_{i}$ denotes the position of the $i^{\text {th }}$ employed bee, $S$ represents the number of employed bees, and $P_{i}$ is the probability of selecting the $i^{\text {th }}$ employed bee.

$$
x_{i j}(t+1)=\theta_{i j}+\phi\left(\theta_{i j}() t-\theta_{k j}(t)\right)
$$

where $x_{i}$ denotes the position of the $i^{\text {th }}$ onlooker bee, $t$ denotes the iteration number, $\theta k$ is the randomly chosen employed bee, $j$ represents the dimension of the solution and $\phi(\cdot)$ produces a series of random variable in the range $[-1,1]$.

$$
\theta_{i j}=\theta_{i j \min }+r \cdot\left(\theta_{i j \max }-\theta_{i j \min }\right)
$$

where $r$ is a random number and $r \in[0,1]$. 


\section{Flowchart}

The diagrammatic representation of the Bee Hive algorithm is given below:

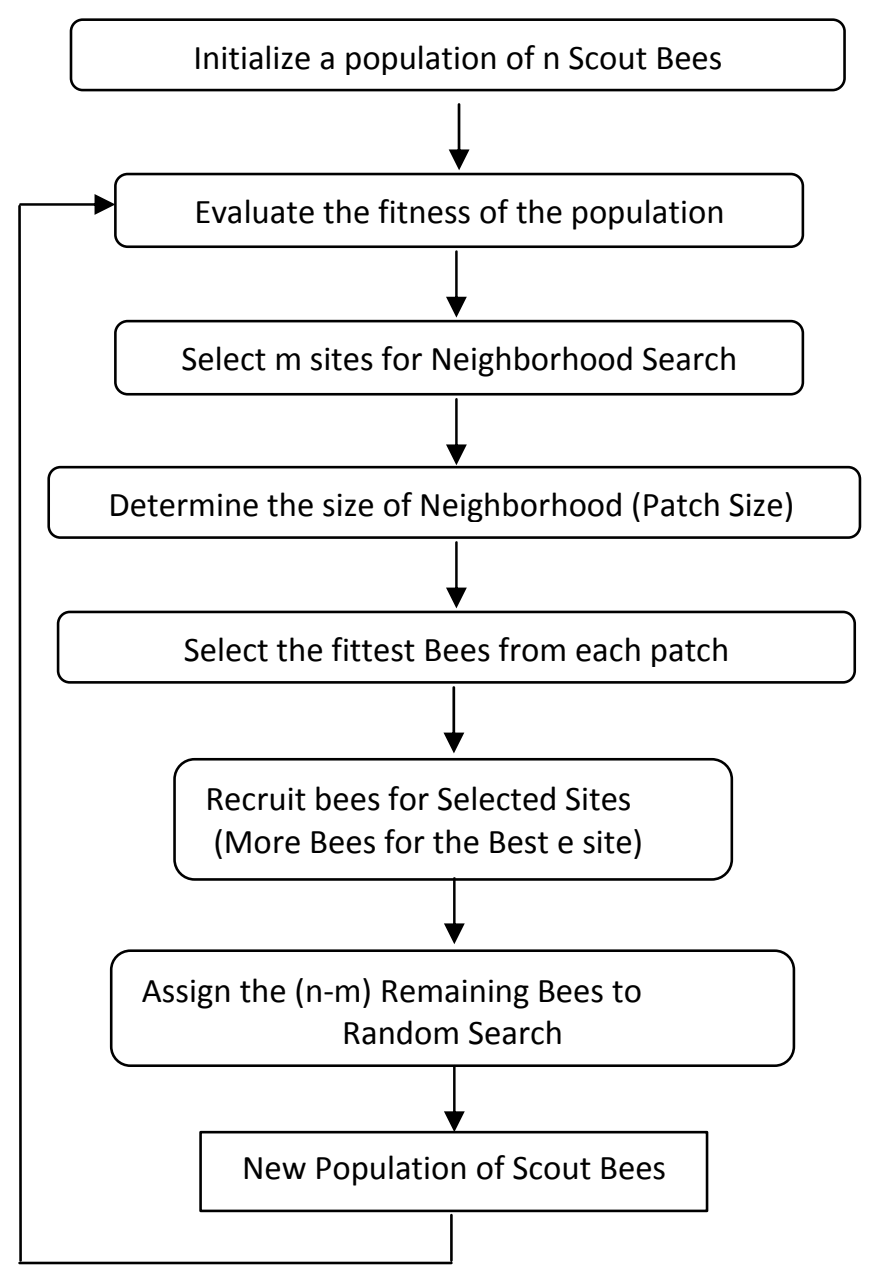

Figure 5.1. Bee Hive Algorithm

\section{Data And Results}

\section{A. TEST CASE I}

3-generator System:

The unit characteristics data are given [1]. The load demand is 850MW. The constraints which have been included are Valve point loading, Ramp Rate Limits, Prohibited Operating zones and transmission losses.

The output power for each generator among the three and Fuel cost for the same has been represented below and also the total power along with the fuel cost has been calculated. Comparison has been made for the calculated result in Bee Hive Algorithm with Genetic Algorithm. 
Table 1. Convergence Results for 3 Generating Units With Valve Point Effect \& Losses

\begin{tabular}{|l|l|r|}
\hline \multirow{2}{*}{\multicolumn{1}{|c|}{ Quantities }} & \multicolumn{2}{c|}{ Optimal Values } \\
\cline { 2 - 3 } & \multicolumn{1}{|c|}{ BHA } & GA \\
\hline P1(MW) & 145.56 & 146.56 \\
\hline P2(MW) & 293.42 & 293.12 \\
\hline P3(MW) & 422.36 & 421.87 \\
\hline F1(\$/hr) & 1365.4 & 1379.4 \\
\hline F2(\$/hr) & 2287.5 & 2584.3 \\
\hline F3(\$/hr) & 4357.1 & 4377.7 \\
\hline Ploss(MW) & 11.139 & 13.139 \\
\hline Total Gen(MW) & 861.34 & 861.55 \\
\hline Total Fuel Cost $(\$ / h r)$ & 8010 & 8341.4 \\
\hline
\end{tabular}

B. TEST CASE II

10-generator systems:

The unit characteristics data are given [1]. The load demand is 2000MW. System data of units considering $b$ loss coefficients are given in [27].

The constraints which have been included in this ten unit system was Valve point loading, Ramp-Rate limits, Prohibited Operating Zones along with Multiple Fuel Switching.

Table 2. Convergence Results for 10 Generating Units With Valve Point Effect

\begin{tabular}{|l|c|c|}
\hline \multirow{2}{*}{\multicolumn{1}{|c|}{ Quantities }} & \multicolumn{2}{c|}{ Optimal Values } \\
\cline { 2 - 3 } & BHA & GA \\
\hline P1(MW) & 195.193 & 225.6242 \\
\hline P2(MW) & 286.109 & 233.7826 \\
\hline P3(MW) & 340 & 330 \\
\hline P4(MW) & 300 & 300 \\
\hline P5(MW) & 243 & 242 \\
\hline P6(MW) & 160 & 160 \\
\hline P7(MW) & 130 & 130 \\
\hline P8(MW) & 120 & 118 \\
\hline P9(MW) & 80 & 80 \\
\hline P10(MW) & 223.236 & 245.9484 \\
\hline $\begin{array}{l}\text { Total Power } \\
\text { Output(MW) }\end{array}$ & 2057.53 & 2056.8752 \\
\hline Ploss(MW) & 57.53 & 56.872 \\
\hline $\begin{array}{l}\text { Total Generation } \\
\text { Cost(\$/h) }\end{array}$ & 123916.573 & 125975.5063 \\
\hline \multicolumn{2}{|l}{} \\
\hline
\end{tabular}

\section{Conclusion}

In this paper, a comprehensives ED model including ramp rate limits, valve loading effects, Multiple Fuels and transmission losses together is presented. In this method, the Bee Hive algorithm method is found best suited for the fuel cost functions of non-smooth, multiple fuel curves when compared with GA. The proposed BHA can provide a more diverse search of solution space and so better optimum solutions with low computation burden can be found. The research work is under way in order to incorporate more security issues of power system in the ED model with other constraints. 


\section{References}

[1] Padmanabhan, Siva Kumar R. S., J. Jasper : "Optimization of piecewise non-linear multi constrained Economic power dispatch problem using an Improved Genetic Algorithm", JEE Trans. Indus elect pow syst., 2010, 10, (3), pp. 106-112

[2] Lee, F. N., and Breipohl, A. M.: "Reserve constrained economic dispatch with prohibited operating zones”, IEEE Trans. Power Syst., 1993, 8, (1), pp. 246-254

[3] Chen, P. H., and Chang, H. C.: "Large-scale economic dispatch by genetic algorithm", IEEE Trans. Power Syst., 1995, 10, (4), pp. 1919-1926

[4] Kim, J. O., Shina, D. J., Parka, J. N., and Singh, C.: "Atavistic genetic algorithm for economic dispatch with valve point effect”, Electr. Power Syst. Res., 2002, 62, (3), pp. 201-207

[5] Walters, D. C., and Sheble, G. B.: "Genetic algorithm solution of economic dispatch with valve point loading”, IEEE Trans. Power Syst., 1993, 8, (3), pp. 1325-1332

[6] J. Wood and B. F. Wollenberg, Power generation, operation and control, New York: Wiley, 1996.

[7] IEEE Committee Report, "Present Practices in the Economic Operation of Power Systems," IEEE Transactions on Power Apparatus and Systems, Vol. PAS-90, July/August 1971, pp. 1768-1775.

[8] C. Walters, G. B. Sheble, "Genetic Algorithm Solution Of Economic Dispatch With Valve Point Loading," IEEE Trans. Power Systems, Vol. 8, No. 3, pp. 1325-1332, August 1993.

[9] K. Wong, Y. Wong, "Genetic and genetic/simulated-annealing approaches to economic dispatch," IEE Proceedings Gener, Trans and Distr, Vol. 141, No. 5, pp. 507-513, Sep 1994.

[10] K. Wong, B. Lau, A. Fry, "Modelling Generator Input-Output Characteristcs with ValvePoint Loading Using Neural Networks," IEE 2nd International Conference on Advances in Power System Control Operation and Management, pp. 843-848, 7-10 Dec 1993.

[11] H. Yang, P. Yang, C Huang, "Evolutionary Programming Based Economic Dispatch for Units with Non-Smooth Fuel Cost Functions," IEEE Trans. Power Systems, Vol. 11, No. 1, pp. 112-118, February 1996.

[12] J. Park; K. Lee; J. Shin; K. Lee, "A particle swarm optimization for economic dispatch with nonsmooth cost functions," IEEE Trans. On Power Systems, Vol. 20, No. 1, pp. 3442, Feb. 2005.

[13] E. Lin, G. L. Viviani, "Hierarchical Economic Dispatch for Piecewise Quadratic Cost Functions," IEEE Trans. Power Apparatus and Systems, Vol. PAS-103, No. 6, pp. I 1 701175, June 1984.

[14] El-Gallad, M. El-Hawary, A. Sallam, A. Kalas, "Swarm Intelligence for Hybrid Cost Dispatch Problem," Canadian Conf. on Electrical and Computer Engineering, Vol. 2, pp. 753-757, 13-16 May 2001.

[15] W. Lin, F. Cheng, M. Tsay, "Nonconvex Economic Dispatch by Integrated Artificial Intelligence," IEEE Trans. on Power Systems, Vol. 16, No. 2, pp. 307-311, May 2001.

[16] J. Park, S. Yang, K. Mun, H. Lee, J. Jung, "An application of evolutionary computations to economic load dispatch with piecewise quadratic cost functions," The 1998 IEEE International Conference on Evolutionary Computation, Vol. 8, No. 3, pp. 289-294, 4-9 May 1998.

[17] K. Y. Lee, A. Sode Yone, J. Ho Park, "Adaptive Hopfield Neural Networks for Economic Load Dispatch," IEEE Trans. on Power Systems, Vol. 13, No. 2, pp. 519-526, May 1998.

[18] N. Lee, A. M. Breipohl, "Reserve Constrained Economic Dispatch With Prohibited Operating Zones," IEEE Trans. Power Systems, Vol. 8, No. 1, pp. 246-254, February 1993.

[19] J. Y. Fan, J. D. McDonald, "A Practical Approach to Real Time Economic Dispatch Considering Unit's Prohibited Operating Zones," IEEE Trans. Power Systems, Vol. 9, No. 4, pp. 1737-1743, November 1994. 
[20] S. 0. Orero, M. R. Irving, "Economic Dispatch Of Generators With Prohibited Operating Zones: A Genetic Algorithm Approach," IEE Proceedings - Gener. Transm. Distrib., Vol. 143, No. 6, pp. 529-534, November 1996.

[21] P. Chen, H. Chang, "Large-Scale Economic Dispatch by Genetic Algorithm," IEEE Trans. on Power Systems, Vol. 10, No. 4, pp. 1919-1926, November 1995.

[22] T. Jayabarathi. G. Sadasivam, V. Ramachandran, "Evolutionary Programming Based Economic Dispatch of Generators with Prohibited Operating Zones," Electric Power Systems Research, Vol. 52, No. 3, pp.261-266, December 1999.

[23] Pancholi R. K, Swarup K. S., "Particle swarm optimization for security constrained economic dispatch”. In: Presented at International Conference on Intelligent Sensing and Information Processing. (IEEE Cat. No. 04EX783), Chennai, India; 2004.

[24] EL-Sharkawy M, Nieebur D., "Artificial neural networks with application to power systems,” IEEE Power Eng Soc, A Tutorial Course 1996.

[25] Yalcinoz T, Short M. J., "Neural networks approach for solving economic dispatch problem with transmission capacity constraints”, IEEE Trans Power Syst 1998;13:30713.

[26] Youssef H. K., El-Naggar K. M., "Genetic based algorithm for security constrained power system economic dispatch”, Elect Power Syst Res 2000;53:47-51.

[27] Chao-Lung Chiang, "Improved Genetic Algorithm for Power Economic Dispatch of Units With Valve-Point Effects and Multiple Fuels", IEEE Trans. Power Systems, Vol. 20, No. 4, November 2005

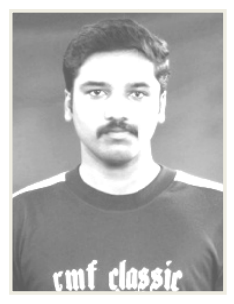

B. Padmanabhan was born on June 26, 1989. He is doing his M.E. (Power Systems Engineering) degree in Sardar Raja College of Engineering, Tirunelveli Dist, TamilNadu, India.

His area of interest includes power system optimization, and Soft Computing Techniques.

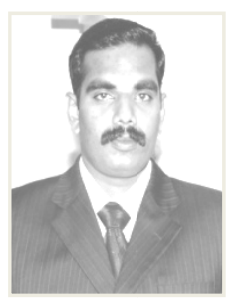

J. Jasper was born on February 28, 1981. He is currently working toward the Ph.D. degree with the Faculty of Electrical Engineering, Anna University of Technology, Coimbatore, India.

$\mathrm{He}$ is presently an Associate Professor in the Department of Electrical Engineering, Ponjesly College of Engineering, and TamilNadu, India.

His major research interest includes power system operation, Distributed Generation, intelligent control and Electrical Machines.

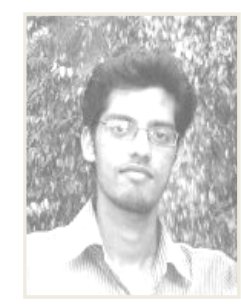

Siva Kumar R. S. was born on May 12, 1988. He is doing his M.E. (Power Systems Engineering) degree in Anna University of Technology, Coimbatore, TamilNadu, India.

His area of interest includes power system optimization and Artificial Intelligence. 